\title{
On Solving Mathematical Problems the Spatial-Visual Ways
}

\author{
Sheena Mai A. Galman \\ Faculty of Mathematics, College of Education, Nueva Ecija University of Science and Technology, Cabanatuan City, Philippines \\ Email: subiagener@yahoo.com
}

How to cite this paper: Galman, S.M.A. (2019) On Solving Mathematical Problems the Spatial-Visual Ways. Journal of Applied Mathematics and Physics, 7, 559-566. https://doi.org/10.4236/jamp.2019.73041

Received: February 25, 2019

Accepted: March 17, 2019

Published: March 20, 2019

Copyright $\odot 2019$ by author(s) and Scientific Research Publishing Inc. This work is licensed under the Creative Commons Attribution International License (CC BY 4.0).

http://creativecommons.org/licenses/by/4.0/

\begin{abstract}
This study investigated the effectiveness of spatial-visualization-based instruction on the mathematical problem-solving performance of $35 \mathrm{ma}$ thematics education students using one-group pretest-posttest quasi-experimental design. It also aimed to describe how spatial visualization is applied in solving mathematical problems. The findings of the study revealed that spatial-visualization-based instruction improved the mathematical problem-solving performance of students. The spatial-visualization ability can be applied in solving mathematical problems.
\end{abstract}

\section{Keywords}

Mathematical Problem-Solving Performance, Spatial-Visualization Ability, Spatial-Visualization-Based Instruction, Quasi-Experimental Design

\section{Introduction}

Mathematics is an abstract science. Oftentimes, students find difficulties in learning the subject because of the complexity of using symbols and computations. Also, students tend to forget previously learned concepts and skills that are necessary for the new skills to be learned. As a result, students lack the needed knowledge and comprehension to advance to the next level of study.

Since mastery of mathematics is a key literacy component that influences children's success in education and in future society [1], teachers focused on enabling children to succeed at school [2]. Some teachers venture on a very unique method of teaching that provides a meaningful, enjoyable and engaging experience to learners [3]. Others are creative in their thinking and in their approaches [4] as cited in [5] in order for their students to learn better. Likewise, teachers must also assist students by designing and developing instruction which 
can help in concretizing every mathematical concept. Students may understand the concept if they clearly see the idea of using concrete things such as mathematical tools, visuals, and models. But still, there are students who fail to look into the appropriate use of visuals and models because of poor, incomplete or wrong illustration such as labeling and use of appropriate figures. Thus, they end with poor understanding and incorrect solutions to problems.

"Teaching students how to solve word problems remained the most difficult assignment facing mathematics teachers" [6]. Researchers have long been engaged in the development and testing of teaching strategies that could be used in teaching problem solving and a review of their findings indicates inconclusive or conflicting results.

Problem-solving performance may be a function of the spatial visualization ability, an intellective factor. Spatial visualization has been found as a mediator in problem-solving. The author in [7] "concluded that the use of schematic spatial representations was associated with success in mathematical problem solving". Several other studies have shown that spatial ability is required for success in mathematics. Spatial-visualization ability correlates highly with problem-solving performance. However, very few, if ever, of these studies dealt in training spatial visualization and how these pieces of training affect problem-solving ability of students, particularly in the field of mathematics.

Logical-Mathematical intelligence is the ability to think logically, detect patterns, scientific reasoning and deduction; analyze problems, perform mathematical calculations and understand the relationship between cause and effect towards a tangible outcome or result. Whereas, Spatial-visualization intelligence is the ability to interpret and create visual images; pictorial imagination and expression; understand the relationship between images and meanings, and between space and effect. A person who is weak spatially and strong numerically will be more likely to develop spatial ability if it is explained and developed by using numbers and logic and not by asking them to pack a suitcase in front of an audience [8]. Hence, a person can have more than one intelligence and so, be logical-mathematically and spatial-visually intelligent at the same time.

Without well-developed spatial ability, a person may encounter serious problems affecting one's academic pursuit or career. The researchers in [9] emphasized that findings from the experimental studies thereof have established evidence that the spatial visualization ability is trainable when pieces of training are designed with a specific focus in this ability Hence, it appears that spatial ability is a highly trainable aptitude and is linked with the problem-solving performance. Such was supported by [10] when she has stated that in the event that interventions have occurred to improve the spatial-visualability of students, pieces of training have been successful.

Hence, premises considered, this study was conceptualized to describe how spatial-visualization ability can be developed in spatial-visual-based instruction and how such can be used in mathematical problem-solving. 


\section{Methods}

The study employed the one-group pretest-posttest quasi-experimental design wherein "a single group of participants or subjects undergoes pretest and posttest". The pretest is given at the beginning of the treatment or independent variable manipulation. The posttest is given at the end of the treatment. "If there exists a significant difference between the pretest and posttest scores, such may be attributed to the independent variable" [11] as cited in [12].

The subjects of this study were 35 mathematics education students who formed an intact class. Informed consent was secured from them by the researcher before the conduct of the experiment in observance of the ethical considerations. The experiment was conducted within three weeks.

The Problem Solving Test in Mathematics (PSTM) and Solving Mathematical Problems the Spatial-Visual Ways Plan (SMP-SVW) were used as instruments of the study. The PSTM is a 24-item teacher-made test designed to measure the problem-solving performance of the subjects before and after the instruction. It contains items on age, distance, motion, geometry and work-related problems. It is a multiple choice type of test with four options provided in each item. The test underwent a test of validity and reliability.

On the other hand, the SMP-SVW consists of tasks on Transformations, Topological Relations, Projective Representation, Conservation and Frames I \& II, Embedded Figures, Grid and Percent It, and Shape-to-Shape. Five of these were performed individually, while the remaining tasks were performed by the group. This served as the basis for the design of the Spatial-Visualization-based class, which lasted for ten sessions.

Frequency count, percentage, weighted mean, and t-test were used as statistical tools. The experimental procedure lasted for 10 weeks.

\section{Results}

\subsection{Students' Performance before the Spatial-Visualization-Based Instruction}

Student's performance in solving mathematical problems before the spatial-visualization-based instruction is presented in Table 1.

Fifteen (42.9\%) got scores within the interval of 5 - 9, which may be verbally interpreted as fairly satisfactory. There were 14 (40.0\%) who got scores ranging from 10 to 14 , which means that they satisfactorily performed in the pretest. Only six (17.1\%) performed very satisfactorily having scores within the interval of $15-19$.

Upon examining the responses of the students, it was found that many of them leave some items blank, without any attempt to answer the test items. Some made responses by simply writing the given data drawn from the problems, while some made attempts on answering by stating what they considered as relevant and appropriate formula, carried on the computations straight away and made some sketches of figures. However, examining the figures sketched, it 
can be deduced that they did not know how to apply their spatial-ability in solving the problems. That is, they had drawn inappropriate figures, and if appropriately drawn, such figures were incorrectly labeled. Further, they cannot discriminate symbols well.

In their study, the authors in [13] discussed that "difficulties in mathematics problem solving can be caused by major mathematics skills and cognitive abilities in learning. Data findings showed that students lacked in many math skills such as number-fact, visual-spatial and information skills". The deficiency of these mathematics skills and also of cognitive abilities in learning inhibits the mathematical problem-solving. It follows that students with a deficiency in visual-spatial skill have a low probability of performing well in mathematical problem-solving. Further, [14] found that "learners with low spatial abilities are more challenged geometry learners. Hence, it was identified that instructional activities with a focus on fostering spatial abilities must be included in the instruction".

\subsection{After the Spatial-Visualization-Based Instruction}

Students' performance in solving mathematical problems after spatial-visualizationbased instruction is presented in Table 2.

Notice that $20(57.1 \%)$ students did an excellent performance in the posttest with scores that ranged from 20 to 22 , while 14 (40.0\%) showed very satisfactory performance with scores that ranged from 17 to 19 . Only one $(2.9 \%)$ performed satisfactorily.

Table 1. Performance of the students before the spatial-visualization-based instruction.

\begin{tabular}{cccc}
\hline Score & Verbal Description & Frequency & Percent \\
\hline $0-4$ & Needs Improvement & 0 & 0.00 \\
$5-9$ & Fairly Satisfactory & 15 & 42.9 \\
$10-14$ & Satisfactory & 14 & 40.0 \\
$15-19$ & Very Satisfactory & 6 & 17.1 \\
$20-24$ & Excellent & 0 & 0.00 \\
Total & & 35 & $100 \%$ \\
\hline
\end{tabular}

Table 2. Performance of the students after the spatial-visualization-based instruction.

\begin{tabular}{cccc}
\hline Score & Verbal Description & Frequency & Percent \\
\hline $0-4$ & Needs Improvement & 0 & 0.0 \\
$5-9$ & Fair & 0 & 0.0 \\
$10-14$ & Satisfactory & 1 & 2.9 \\
$15-19$ & Very Satisfactory & 14 & 40.0 \\
$20-24$ & Excellent & 20 & 57.1 \\
Total & & 35 & $100.0 \%$ \\
\hline
\end{tabular}


The improvement as to the scores of the students can be deduced from the data gathered. Such result of the study is similar to the result of the study conducted by [15] as they investigated on the effects of a spatial intervention on the calculus performance of students who failed a mental rotation (MR) test. It was found out that their performance was improved after being subjected to the intervention.

The students' solutions contained responses showing properly labeled illustrations, figures with reasonable proportion as to measurements/dimensions of its parts. Many students resorted on the use of drawings and illustrations on solving the problems rather than merely performing computations and applying formulas.

For instance, on solving a time problem, one of the students applied the use of number lines in answering. He used two lines to represent separately the dates it took for the subjects to do a task. Both lines started from zero and changed in positions relative to the dates. Both were correctly accompanied with the given numbers, as indicated in the problem. The changes in the dates at a time were described using lines with arrowheads until the student came with the common date, which reflected his final answer, the correct answer.

\subsection{Comparison of the Performance of Students on Solving Mathematical Problems before and after the Spatial-Visualization-Based Instruction}

Table 3 shows the comparison of the performance of students on solving mathematical problems before and after the spatial-visualization-based instruction.

The computed $t$ value of 18.84 is significant at $1 \%$ level, hence, there is enough statistical evidence to conclude that there is a significant difference between the mean scores of the students in the pre-test and post-test. Therefore, the performance of the students after the visual-spatial instruction is significantly better than their performance before the same.

Applying Transformation on solving mathematical word problems, spatial-visualization ability may be applied by choosing as to which among the reflection, translation, or rotation may be used. Such can be applied in answering problems on graphs. On the other hand, on solving a problem on the reflection of a triangle, an illustration was drawn, with $y$-axis as the line of reflection and thus justified that the image formed on the right side of it with vertices, as in the case, A', B', and C' was the reflected image of the pre-image with corresponding vertices, $A, B$, and $C$, respectively.

In the case of translating a parabola, an illustration was made to show the difference between the graph of a quadratic equation before the translation and its graph after the translation, the graph is accompanied by correct labels which suggest clarity of the solution of the problem. The integers along the two axes clearly suggest the location of the possible coordinates in the Cartesian plane, most significant of which is the vertex of the translated graph. The vertices of the graph before and after translation were correctly located. 
Table 3. Comparison of students' performance before and after the spatial-visualization-based instruction.

\begin{tabular}{ccc}
\hline Test & Pretest & Posttest \\
\hline Mean & 10.9429 & 20.0857 \\
Variance & 13.3496 & 4.1983 \\
$\mathrm{t}-$ stat & & $18.84^{* *}$ \\
\hline
\end{tabular}

${ }^{* *}$ difference is significant at 0.01 level.

On solving a Geometry problem involving Similar Triangles, instead of simply performing computations, a student drew two triangles that were correctly labeled by corresponding measurements. Such facilitated the ease of determining the missing values that were needed to be determined in order to solve for the perimeter of one of the triangles.

In another mathematical problem, specifically Percentage problem, one student used a 10 by 10 grid to answer the problem as to the amount of rainfall a particular place was receiving in a certain month. A portion of the grid represents a certain quantity which is indicated in the shaded region. The whole grid represents the quantity being asked based on the quantity represented by the shaded region. The student was able to use a grid to solve the mathematical problem without performing computation and algebraic manipulation.

It can, therefore, be deduced that mathematical problems can be answered by applying the spatial-visualization ability. That is, instead of traditionally identifying formula, performing algebraic manipulations, and carrying out computations, illustrations and figures can be used. Spaces, symbols, and dimensions can be used to answer mathematical problems. However, since not all students know how to apply such ability, teaching them how to do so may be considered as in the present study. An instruction that is spatial-visual-based may be considered.

The findings of the study are similar to that of [16] as they reviewed the evidence as to the effectiveness of spatial training on Science, Technology, Engineering, and Mathematics (STEM) achievement and degree attainment. It was found that spatial training increased students' success in STEM fields and such training consequently improve retention, achievement, and degree attainment. Further, the findings of the study conducted by authors in [17] show that the mathematical spatial visualization ability of students who are exposed to intervention has high improvement level on overall mathematical knowledge. Similarly, [18] studied the use of visual imagery and its relationship to spatial visualization ability of the students while solving mathematical word problems. The use of visual images was found to be significantly correlated with spatial visualization measure. Such was also found to be positively correlated with higher mathematical word problem-solving performance.

\section{Conclusions and Recommendations}

Results of the study imply that spatial-visualization-based instruction improves 
the mathematical problem-solving performance of students as shown by their better and improved scores in the problem-solving test. In addition, the students learned how to use their spatial-visualization ability in mathematical problem-solving. As stated by [19] "visualization is a reasoning activity in mathematics".

As to recommendations, teachers of mathematics subjects may look into the possibility of incorporating the use of spatial-visualization into their content courses. This calls for the introduction of teaching mathematics using the integration of spatial visualization. The use of visuals and illustrations as well as mathematical models and materials to manipulate during class discussion may also provide them experiences that lead to learning. This may give way in providing an atmosphere which will encourage active exploration. However, since this study employed only one group of pretest-posttest quasi-experimental design, the researcher recommends the conduct of a replication of the study using two groups of respondents-an experimental and a control group.

\section{Conflicts of Interest}

The author declares no conflicts of interest regarding the publication of this paper.

\section{References}

[1] Engle, P., Grantham-McGregor, S., Black, M., Walker, S. and Wachs, T. (2007) How to Avoid the Loss of Potential in over 200 Million Young Children in the Developing World. Child Health and Education, 1, 67-87.

[2] Coombes, C. (2017) What Is Effective Teaching of Mathematics? https://www.generationready.com/what-is-effective-teaching-of-mathematics/

[3] Subia, G.S. (2018) Think Like My Teacher (TLMT): A New Method in Assessing Millennial Learners. International Journal of Arts Humanities and Social Sciences, 3, 57-61. http://www.ijahss.com

[4] Crockett, L. (2015) Seven Characteristics of an Innovative Educator. Global Digital Citizen Foundation.

[5] Subia, G.S. (2018) Comprehensible Technique in Solving Consecutive Number Problems in Algebra. Journal of Applied Mathematics and Physics, 6, 447-457. https://doi.org/10.4236/jamp.2018.63041

[6] Castro, F. (1991) The Effects of Spatial Visualization Training and Mathematics Anxiety Reduction Program in the Performance of Engineering Students in Solving Word Problems in Algebra. Unpublished.

[7] Hegarty, M. and Kozhevnikov, M. (1999) Types of Visual-Spatial Representations and Mathematical Problem Solving. Journal of Educational Psychology, 91, 684-689. https://doi.org/10.1037/0022-0663.91.4.684

[8] Gardner, H. (2006) Multiple Intelligences: New Horizons. Basic Books, New York.

[9] Rafi, A., Samsudin, K.A. and Said, C.S. (2008) Training in Spatial Visualization: The Effects of Training Method and Gender. Educational Technology \& Society, 11, 127-140. http://www.ifets.info/journals/11_3/10.pdf

[10] Sorby, A. (2009) Educational Research in Developing 3-D Spatial Skills for Engineering Students. International Journal of Science Education, 31, 459-480. 
https://doi.org/10.1080/09500690802595839

[11] Colman, A. (2015) A Dictionary of Psychology. 4th Edition, Oxford University Press, Oxford.

[12] Del Rosario, J., Subia, G. and Lopez, C. (2018) Preparing Junior High School Students in Science, Technology, Engineering and Mathematics Track Using Journal Writing in Mathematics. International Journal of Advanced Engineering, Management and Science, 4, 749-752. https://doi.org/10.22161/ijaems.4.11.1

[13] Tambychik, T. and Meerah, T.S.M. (2010) Students' Difficulties in Mathematics Problem-Solving: What Do They Say? Procedia-Social and Behavioral Sciences, 8 , 142-151.

[14] Unal, H., Jakubowski, E. and Corey, D. (2009) Differences in Learning Geometry among High and Low Spatial Ability Pre-Service Mathematics Teachers. International Journal of Mathematical Education in Science and Technology, 40, 997-1012. https://doi.org/10.1080/00207390902912852

[15] Sorby, S., Casey, B., Veurink, N. and Dulaney, A. (2013) The Role of Spatial Training in Improving Spatial and Calculus Performance in Engineering Students. Learning and Individual Differences, 26, 20-29.

https://doi.org/10.1016/j.lindif.2013.03.010

[16] Stieff, M. and Uttal, D. (2015) How Much Can Spatial Training Improve STEM Achievement? Educational Psychological Review, 27, 607.

https://doi.org/10.1007/s10648-015-9304-8

[17] Susilawati, W., Syuryadi, D. and Dahlan, J. (2017) The Improvement of Mathematical Spatial Visualization Ability of Student through Cognitive Conflict. International Electronic Journal of Mathematics Education, 12, 155-166.

[18] Van Garderen, D. (2006) Spatial Visualization, Visual Imagery, and Mathematical Problem Solving of Students with Varying Abilities. Journal of Learning Disabilities, 39, 496-506. https://doi.org/10.1177/00222194060390060201

[19] Gutiérrez, A. (1996) Visualization in 3-Dimensional Geometry: In Search of a Framework. In: Puig, L. and Guttierez, A., Eds., 20 th International Group for the Psychology of Mathematics Education, Vol. 1, Universidad de Valencia, Valencia, 3-19. 